\title{
Uma lanterna bruxuleante: a representação da UDN durante a criação da Petrobras na grande imprensa carioca (1952-1953)
}

\author{
Luis Carlos dos Passos Martins* \\ Thiago Costa**
}

Palavras-chave:
Imprensa
Política
Vargas

Keywords:

Press

Ppolicy

Vargas

\begin{abstract}
Resumo: Este trabalho pretende discutir a forma como alguns jornais cariocas representando diferentes matizes ideológicas (Correio da Manhã, Diário de Notícias e Última Hora) representaram o papel da União Democrática Brasileira (UDN) no processo de criação da Petrobras (1951-1953). Este tema se justifica pela sinuosa e surpreendente postura do partido no processo, que oscilou desde a defesa da "Campanha O Petróleo É Nosso" até a tentativa de implantar um modelo liberal de exploração petrolífero no país, passando pela proposta de fundação de uma empresa pública para o setor (ENAPE). Dessa forma, esta questão oferece uma boa oportunidade para testar algumas hipóteses sobre a relação entre a imprensa e a política no período, especialmente no que se refere à interpretação que afirma que os jornais ditos "liberais" eram invariavelmente udenistas e antivarguistas.
\end{abstract}

\begin{abstract}
This research intends to analyze how some daily newspapers from Rio de Janeiro, which represented different ideological influences (Correio da Manhã, Diário de Notícias e Última Hora) have presented the role of the UDN party in the process behind the Petrobras creation (1951-1953). The choice of this theme justifies itself for the rather tortuous and surprising stnding followed by União Democrática Brasileira - UDN (Brazilian Democratic Union) in that process, which oscilated between its passionate defense of the "Oil is Ours campaign", later throwing its support towards the implementation of a market-oriented oil policy, after finally settling supporting the creation of a state-owned oil company (ENAPE). Therefore, the analysis of this issue offers us with a good opportunity to test some of our hypotesis about on the relatioship between press and politics during that period, espacially in what concerns the prevailing historiographical notion that the so called "iberal newsapers" were always pro UDN and against Vargas.
\end{abstract}

Recebido em 15 de março de 2017. Aprovado em 02 de agosto de 2017.

\section{Introdução}

O presente artigo pretende estabelecer uma reflexão inicial sobre o tema da relação entre política e imprensa durante o Segundo Governo Vargas (1951-1954). Este tema já é bastante abordado pela historiografia correspondente ao período; mas, ao nosso entender, de forma bastante limitada, quando não equivocada. No geral, os trabalhos dedicados ao assunto tendem a se basear e, ao mesmo tempo, sustentar duas premissas: a) a "imprensa" teve um papel ativo e decisivo na derrubada do governo Vargas, atuando de maneira incessante e relativamente uníssona na busca deste objetivo desde o início do mandato de Getúlio, ao menos no que se refere à chamada "imprensa conservadora ou liberal" (SILVA, 1978; SODRÉ, 1983); b) a relação entre imprensa e política pode ser suficientemente compreendida considerando-se os jornais como instrumentos a serviço dos partidos e/ou grupos de pressão (políticos, econômicos), que, em última instância, financiavam os seus empreendimentos (LAURENZA, 1998; RIBEIRO, 2003).

Algumas pesquisas têm procurado destoar dessa linha interpretativa, como é o caso do trabalho de Abreu eLattmann-Welltmann (1994), cuja análise

\footnotetext{
* Pós-Doutor em História pela Pontifícia Universidade Católica do Rio Grande do Sul (PUC-RS), professor adjunto do Departamento de História e do Programa de Pós-Graduação em História da PUC-RS. Coordenador do Curso de História da PUC-RS. Vice-Coordenador do GT de Política da da Associação Nacional de História (ANPUH). E-mail: luis.martins@pucrs.br.

** Graduando do Curso de História na instituição Pontifícia Universidade Católica do Rio Grande do Sul (PUC-RS).

E-mail: thiago.regina@acad.pucrs.br.
} 
sobre o posicionamento da grande imprensa diante da crise final do Segundo Governo Vargas levou os autores a concluírem que a ideia de uma oposição sistemática e uniforme dos "grandes jornais" a Getúlio deveria ser, no mínimo, relativizada. Para compreender de forma mais adequada o processo, especialmente no que se refere à postura mais "moderada" de jornais como O Globo e o Correio da Manhã, Abreu e Lattmann-Welltmann sugerem a introdução na análise de outras variáveis, como a adoção por alguns periódicos de princípios da imprensa anglo-saxônica como "neutralidade" e "objetividade" jornalística como estratégia mercadológica.

O caminho aberto por este tipo de trabalho, porém, não recebeu a devida continuidade, ficando os estudos voltados ao tema política e imprensa no período em questão ainda presos ao modelo citado acima, que podemos caracterizar pois dois limites analíticos graves: o uso incessante do "paradigma da manipulação da notícia"1 e uma visão dos grandes jornais que os reduz à condição de "porta-vozes" dos poderes estabelecidos na sociedade. ${ }^{2}$

Dessa maneira, o trabalho aqui apresentado pretende dar continuidade a linha de análise aberta por Abreu e Lattmann-Welltmann (1994) e Abreu e Lattmann-Welltmann (1996), procurando compreender a relação entre a imprensa e política no Segundo Governo Vargas para além do modelo acima referido. Todavia, tendo em vista o escopo limitado do artigo, optamos por analisar um caso particular e, a partir dele, fazer algumas reflexões sobre o tema geral, que está sendo objeto de um projeto mais amplo.

Com estes objetivos em vista, iremos analisar a forma como a ação da União Democrática Brasileira (UDN) no processo de criação da Petrobras (1951-1953) foi representada por parte da grande imprensa carioca. Escolhemos este tema tendo em vista a participação bastante ativa e, digamos, até surpreendente do "partido do Brigadeiro" neste processo, um dos mais controversos do período.

Com efeito, quando Vargas apresentou o seu programa do petróleo, em dezembro de 1951, propondo a criação de uma empresa de economia mista - a Petróleos Brasileiros S.A. - que admitia em seu quadro acionário a participação de capital privado, inclusive estrangeiro, foi alvo de inúmeras críticas. ${ }^{3}$ As mais contundentes saíram da Campanha do Petróleo É Nosso, que classificou a proposta de Getúlio de "entreguista". Membros da "ala nacionalista do Exército" entrincheirados no Clube Militar e até parlamentares do Partido Trabalhista Brasileiro (PTB), partido do governo, tomaram as ruas e as tribunas em protesto contra a Petrobras, considerada como porta de entrada dos trustes na exploração do petróleo nacional (MOURA, 1986; WIRTH, 1973).

A UDN, interessada em se contrapor politicamente a Vargas, abandonou a linha liberal e favorável ao capital estrangeiro na exploração do petróleo nacional com a qual vinha se identificando desde o governo Dutra (1946-1950) e aderiu à tese do monopólio estatal para o setor petrolífero. Mais do que isto, além de endossar os argumentos "nacionalistas" que combatiam o suposto "entreguismo" do governo, propôs ainda na Câmara dos Deputados, em 6 de maio de 1952, a criação da ENAPE (Empresa Nacional de Petróleo), uma companhia que teria o monopólio estatal completo da indústria do petróleo brasileira, incluindo até a encampação das refinarias privadas país. Ademais, durante os debates na Câmara Baixa (junho a setembro de 1952), o "partido do Brigadeiro" se manteve firme na defesa da tese monopolista, obrigando o governo, por intermédio do líder da maioria, Gustavo Capanema (PSD), a costurar um acordo com a "oposição" - na qual estava inclusa o próprio PTB - para aprovar o projeto de Vargas mediante a inserção do monopólio do petróleo no acordo. Embora fosse um monopólio considerado "moderado" ou "parcial", porque não incluía o setor de distribuição, acabou sendo considerável um "recuo" do governo, cujo resultado final desagradou tanto Vargas quanto sua Assessoria Econômica para a Presidência que elaborou a proposta (WIRTH, 1973; PEREIRA, 1975).

Entretanto, quando o tema passou a ser analisado no Senado, os senadores udenistas deram um "giro de $180^{\circ}$ " e passaram a rechear o projeto com emendas "liberalizantes", ao ponto de descaracterizá-lo totalmente. Mais do que isto, 
ainda detiveram o documento sob exame durante quase um ano. Retornando à Câmara dos Deputados apenas em julho de 1953, a Petrobras somente foi aprovada em 19 de setembro do mesmo ano, após a retirada das emendas "liberalizantes" com o apoio inusitado dos próprios deputados udenistas.

Dessa maneira, tendo em vista a complexidade política que o tema apresenta, podemos concluir que este tópico apresenta muita relevância para analisar como a imprensa carioca representou a atuação da UDN, não apenas frente à questão do petróleo, mas também frente ao próprio governo Vargas. Ademais, este objeto oferece um interessante campo de pesquisa para testar algumas hipóteses, especialmente no que se refere à identificação da UDN com setores da imprensa considerados "liberais" pela historiografia brasileira. Para tanto, escolhemos três periódicos representativos das principais correntes ideológicas envolvidas no debate na conjuntura em questão: o Correio da Manhã, visto como liberal e favorável ao capital estrangeiro no setor petrolífero, o Última Hora, trabalhista e defensor dos projetos do governo em suas diferentes fases, e o Diário de Notícias, que havia se posicionado a favor do monopólio estatal do petróleo na discussão em torno do Estatuto do Petróleo proposto pelo ex-presidente Dutra (1948-1949) $)^{4}$. A escolha de jornais com diferentes orientações doutrinárias sobre o tema energético e não apenas entre periódicos considerados liberais ocorreu em razão da maior flexibilidade analítica que este espectro permite nos limites do artigo ${ }^{5}$.

\section{A imprensa e o petróleo}

\section{Última Hora - nos passos de Vargas}

Frente ao projeto inicial de Vargas de criação da Petrobras como uma empresa de economia mista, o jornal Última Hora procurou conciliar a postura doutrinária que estava adotando em relação ao nacional-desenvolvimentismo com os movimentos políticos do governo. Para tanto, representou o projeto varguista como proposta alternativa às teses opostas defendidas por, segundo as palavras do jornal, "comunistas" (monopólio estatal do petróleo) e "entreguistas" (abertura ao capital estrangeiro). Com seu formato intermediário, a Petrobras seria a saída para os problemas econômicos do país e um expediente necessário à justiça social. ${ }^{6}$

Apensar de ter inicialmente como alvo de críticas a "Campanha do Petróleo É Nosso" e as fortes investidas que esta fazia contra o projeto do governo, considerado "entreguista", e contra a figura do próprio Vargas, chamado de "advogado da Standard Oil" (MIRANDA, 1983), logo os olhares do Última Hora se voltaram para a UDN.

Em princípio, o Última Hora não cedeu espaço à postura adotada pelos udenistas em favor do monopólio na reunião do Diretório Nacional da sigla, em 30 de abril de 1952. No entanto, ao se verificar que o partido enveredou por esta linha "nacionalista", o vespertino de Samuel Wainer adotou uma conduta de ataque frontal à proposta udenista, especialmente frente à proposta da criação da ENAPE. O periódico se valeu de argumentos os quais remetiam às contradições entre o passado udenista, defensor de bandeiras liberais como a abertura econômica ao capital estrangeiro, com a postura adotada agora na questão do petróleo. $\mathrm{O}$ jornal também desfraldou acusações associativas entre a UDN e os comunistas, com vista a desqualificar a posição dos correligionários do Sr. Bilac Pinto (ÚlTIMA HORA, 1952b). O editorial de 6 de junho de 1952, por exemplo, depois de qualificar os membros do partido como "grã-finos" e defensores dos "proprietários de Cadilac" e dos "tubarões", afirmou, ainda: "Inesperadamente, porém, velhos e conhecidos reacionários, pés de chumbo do capital colonizador, fizeram coro com os comunistas na campanha contra a 'Petrobras', tachando a iniciativa do governo de 'entreguista' ou antinacionalista” (ÚLTIMA HORA, 1952f, p. 3). ${ }^{7} \mathrm{O}$ jornal ainda criticou a sobreposição de interesses políticos e ideológicos ao exame técnico da questão do petróleo. Conforme o diário, apenas para se opor a Getúlio, a UDN abandonou o seu histórico programa partidário e passou a defensor da tese do monopólio estatal do petróleo no objetivo de sustentar interesses particularistas de seus membros. ${ }^{8}$

Nesta jornada, porém, o Última Hora, além de se constituir em bastião do programa do 
governo, procurou representar a si mesmo como um veículo de comunicação aderente aos "interesses populares", tentando conciliar, assim, ao menos discursivamente, os seus propósitos como empresa jornalística com os objetivos políticos de Vargas. ${ }^{9}$ Além disso, em defesa do programa do governo, em 7 de dezembro de 1951, colocou-se como fonte instrutiva sobre as questões que, segundo a sua opinião, expressavam melhor o interesse coletivo. Da mesma forma, dedicou-se à desconstrução das argumentações "entreguistas" e "comunistas", cujas tentativas de desestabilizar o projeto do presidente não passavam, para o periódico, de atitude antipatriótica e contrária aos interesses da Nação (ÚLTIMA HORA, 1951b, p. 1).

Em conformidade com as estratégias do governo, o Última Hora apresentou uma mudança de orientação, transitando da defesa da empresa de economia mista para advogar a favor de uma solução que incluía o monopólio parcial do petróleo, quando tal alternativa foi proposta pelos líderes governistas no Congresso. Antes mesmo de o acordo costurado por Capanema vir a público, o jornal já mencionava a sua articulação, provavelmente com o intuito de anular os ganhos políticos que a UDN tentava angariar com a ENAPE. Diante da apresentação do substitutivo udenista de criação desta empresa, o diário de Wainer assumiu intensamente a tarefa de promover a efetivação do acordo governista no Congresso, adotando um papel investigativo ao perscrutar os agentes políticos e as suas intenções a fim de concretizar mais do que propriamente descrever a solução que estava sendo acordada. ${ }^{10}$

Quando a arena de debates passou a ser o Senado, o Última Hora defendeu a manutenção das tratativas negociadas na Câmara dos Deputados, fazendo coro aos que se mostravam contrários às medidas liberalizantes. ${ }^{11}$ Diante destas tentativas de abertura ao capital estrangeiro pela Câmara Alta, em 7 de agosto de 1953 o jornal assumiu o papel de entidade mais conciliadora do que gladiadora, como notamos pela posição de um importante articulista do diário, o jornalista Humberto Alencar que fez farta campanha a favor do cumprimento dos acordos da Câmara dos Deputados (ÚlTIMA HORA, 1953i, p. 3). Como estratégia, o jornal se dirigiu aos agentes políticos em apelo para que estes atuassem de acordo com o "bem coletivo" - lembrando aos representantes senatoriais que honrassem as suas responsabilidades para com seus eleitores. E, a fim de alertar que não era obrigatório a um udenista defender a tese liberal no setor do petróleo, em 18 de novembro de 1953 o jornal lembrou os senadores da adesão dos deputados do partido ao monopólio estatal que tanto condenara anteriormente (ÚLTIMA HORA, 1953j, p. 3).

A dedicação à defesa do acordo estabelecido pelos deputados fez com que o periódico insistisse no abandono das discussões ideológicas. Porém, para solucionar o paradoxo entre a sua posição anterior contrária ao monopólio e sua adesão, agora, a esta tese - paradoxo que poderia colocar o jornal diante de um sério problema de credibilidade junto aos leitores -, o Última Hora justificou a nova "bandeira" como uma opção pela "harmonia" entre as diversas forças em luta, mesmo que ela própria não se identificasse ideologicamente com a mesma. Era, acima de tudo, uma "opção pelo Brasil" em torno da qual, pregava-se, todos deveriam dar a sua cota de sacrifício, inclusive o periódico de Samuel Wainer. ${ }^{12}$

\section{O Correio da Manhã - em uma só defesa}

Em consonância com a Última Hora na fase de avaliação do projeto na Câmara Baixa, o Correio da Manhã lançou luzes sobre o debate acerca da questão do petróleo procurando entender - e, assim, aceitar - o projeto de Vargas pelo viés do pragmatismo e não dos enfrentamentos ideológicos. Seguindo uma linha convergente, mesmo que involuntária, com a $U H$, o tradicional matutino carioca salientou que as ambições partidárias não deveriam estorvar uma matéria de perfil estritamente técnico. ${ }^{13}$

O jornal sustentou que a proposta flexível de Vargas contemplava os tópicos indispensáveis à exploração do petróleo no Brasil, comportando ao mesmo tempo a eficiência, ao contar com a participação ativa do capital privado, e a salvaguarda dos interesses nacionais, ao garantir a ingerência do Estado. Ainda que o Correio não tenha se manifestado em total acordo com o plano 
governista do petróleo, sua linha de ação não condiz com a representação de um jornal antivarguista. Como podemos ver no editorial de 8 de dezembro de 1951, quando o diário afirmou que Vargas, ao propor uma empresa de economia mista e não uma estatal, "[...] procurou situar-se naquilo que lhe pareceu ser o ponto ótimo entre a eficácia e a garantia dos interesses nacionais", ou seja, "[...] um nacionalismo acentuado - mais de $70 \%$ do capital serão controlados por órgãos públicos e cidadãos brasileiros - e um estatismo moderado" (CORREIO DA MANHÃ, 1951, p. 4). Ainda, segundo o jornal, "a orientação adotada parece combinar o realismo econômico com a defesa dos interesses nacionais", tendo em vista que o governo "[...] deu à empresa a forma de sociedade anônima, a fim de lhe emprestar a máxima flexibilidade comercial" (CORREIO DA MANHÃ, 1951, p. 4).

A decepção do Correio da Manhã com a atuação udenista foi outro ponto de convergência com a Última Hora, sobretudo no que se referia à suposta negligência da UDN com seus compromissos doutrinários e ao vínculo estabelecido com o comunismo, ainda que apenas por estratégia oposicionista. O Correio da Manhã, além de clamar para que a UDN seguisse o "seu programa" liberal no setor, sugeriu que o "partido do Brigadeiro" liderasse a contestação da "Campanha do Petróleo é Nosso” (CORREIO DA MANHÃ, 1952a, p. 4). As críticas do Correio da Manhã à tese udenista ficaram particularmente evidentes em 11 de maio de 1952, na condenação do jornal à "III Convenção do Petróleo", na qual o Centro de Estudos e Defesa do Petróleo e da Economia Nacional (CEDPEN) aderiu ao projeto udenista da ENAPE (CORREIO DA MANHÃ, 1952a, p. 4).

$\mathrm{Na}$ esteira do que já identificamos com a Última Hora, o Correio passou a classificar a postura da UDN como mero "oportunismo político", condenando o partido por agir em favor de suas "conveniências eleitorais" em detrimento dos "interesses da Nação", como podemos perceber no editorial de 9 de setembro de 1952, onde se afirmou:

Contra esse grupo de 'O petróleo é nosso, [...] devem os brasileiros agir com firmeza, com vigilância.
Principalmente porque, por considerações de popularidade fácil, partidos como a UDN vieram engrossar a corrente comunista na oposição ao projeto governamental da Petrobras. (CORREIO DA MANHÃ, 1952d, p. 4).

Em outras palavras, temos o jornal considerado "udenista" e antivarguista em pleno combate à posição assumida pela UDN e em franca associação à proposta de Vargas nesta etapa do processo de criação da Petrobras. Constatação que deve servir, ao menos, para colocar dúvidas sobre as associações lineares que se fazem entre o Correio da Manhã e o "partido do Brigadeiro".

De outra parte, na medida em que partidos como a UDN falhavam em sua missão de combater a "Campanha do Petróleo É Nosso" e a tese do monopólio estatal do petróleo, o Correio da Manhã tomou para si o protagonismo de lutar contra esta proposta. De forma sintomática, em 6 de julho de 1952 defendeu com estes termos a importância da campanha que decidiu adotar em suas páginas:

\section{Este jornal se propõe a fazer um esforço de esclarecimento da opinião pública. Mostraremos que a participação estrangeira, devidamente controlada, é a mais vantajosa forma para a exploração do petróleo. [...] Conhecemos a onda que vai desencadear nossa atitude. Sabemos que o PCB e suas linhas auxiliares mobilizarão contra nós todo o seu poder difamatório. Não será por isso, no entanto, que deixaremos de cumprir nosso dever de bem informar o público e de defender os interesses do país. (CORREIO DA MANHÃ, 1952b, p. 4).}

Como vemos no trecho citado, o eixo argumentativo do Correio da Manhã passa a ser a defesa da participação estrangeira na exploração do petróleo brasileiro, tendo em vista as carências nacionais, tanto em recursos técnicos, quanto em financeiros. Entretanto, como uma espécie de "vacina ideológica", esse jornal procurou salientar que pleitear a participação internacional não significava cegar os seus olhos frente aos possíveis inconvenientes desta presença, como os desvios dos lucros extraídos da exploração petrolífera para além 
dos interesses do país. Por isso, naquele momento, o Correio da Manhã destacou que a atuação do Estado ainda seria bem-vinda como reguladora da participação estrangeira, classificando a sua própria posição como de um "liberalismo moderado", contrastando com orientações do liberalismo mais "radical" (ou neoliberalismo, como já se dizia na época) favorável às vantagens comparativas e defensor da "vocação agrícola do Brasil".

Em resumo, durante os debates na Câmara Baixa, ao Correio da Manhã se atribuiu o papel de instrumento esclarecedor da opinião pública sobre a importância da empresa mista como solução adequada ao país. Porém, quando o projeto do governo foi aprovado com a inclusão do monopólio estatal do petróleo, esse jornal não escondeu a sua decepção, especialmente com Vargas, porque este, na esteira da demagogia udenista, cedeu às hostes "nacionalistas" e abandonou a sua proposta original. ${ }^{14}$

Submetido ao exame do Senado da República, o projeto do petróleo novamente recebeu atenção especial pelo Correio da Manhã em 11 de abril de 1953. Os parlamentares que pleiteavam a incorporação das emendas liberais no plano petrolífero ganharam no jornal um aliado valoroso (CORREIO DA MANHÃ, 1953e, p. 4). O jornal continuou em sua orientação a favor da empresa de economia mista, com espaço para investimentos internos, bem como para a participação técnica e financeira internacional - buscando se afastar do estigma de subordinação aos trustes petrolíferos. Sua meta essencial continuava sendo o combate à solução monopolista vinda da Câmara, para o que, como se percebe, reforçou a sua adesão à proposta inicial de Vargas, não poupando críticas ao governo por ter abandonado o seu próprio projeto. Entretanto, em nossa pesquisa, não encontramos no jornal um destaque ou elogio dado à UDN nas propostas que os senadores fizeram em prol da liberalização do projeto do petróleo. No lugar disto, o jornal preferiu elogiar o Senado como instituição política que cumpria o seu dever patriótico ao possibilitar, segundo o Correio da Manhã do dia 28 de maio de 1953, que este projeto voltasse aos termos originais com que Vargas o apresentou à Nação:
Não se trata mais, portanto, para o Senado, de adotar a fórmula idealmente ótima. Trata-se de evitar ou não a ruína nacional. É um desses momentos em que o Senado é convocado para agir não como ponto de confluência de partidos, mas como suprema instância legislativa do país. (CORREIO DA MANHÃ, 1953f, p. 4).

\section{Diário de Notícias - entre as duas teses}

Inicialmente, quando o programa do petróleo de Vargas foi anunciado, o jornal Diário de Notícias se absteve de externar diretamente a sua orientação doutrinária sobre o tema. Entretanto, o periódico de Orlando Dantas não se eximiu de, na contramão dos jornais antes abordados, rejeitar e desferir densas críticas ao projeto do governo. O jornal acusou a empresa de economia mista proposta por Getúlio de ser vulnerável à invasão de trustes, insinuando, inclusive, que o próprio presidente estaria de "maquinações" com o capital internacional. Em síntese, a grande bandeira do Diário foi o suposto risco de perda da soberania nacional para grupos econômicos estrangeiros aberto pelo programa de Getúlio. ${ }^{15}$

Dessa maneira, na contramão da linha adotada pelos demais órgãos de imprensa, o Diário de Notícias não condenou a interferência política sobre o tema. Ao contrário, na medida em que o projeto varguista pudesse ameaçar a soberania nacional, os debates políticos se tornavam ainda mais necessários, para o jornal. E, no que se refere ao tema específico deste artigo, demonstrou amplo apoioà UDN eà sua proposta de monopólio estatal do petróleo. ${ }^{16}$ Convergentemente com esta alternativa, o periódico de Dantas não procurou contrastar esta posição do "partido do Brigadeiro" com o seu histórico apoio ao liberalismo no setor petrolífero. Mais do que isso, os seus articulistas resgataram o passado udenista de oposição à ditadura de Vargas no Estado Novo, colocando o projeto da ENAPE em uma linha de coerência com esta posição "sólida" antigetulista. ${ }^{17} \mathrm{Ou}$ seja, Getúlio se constituía como o alvo central do periódico em relação ao tema, decorrendo daí a sua busca de aliados no front "nacionalista" contra Vargas, mesmo nas fileiras 
que teriam as menores probabilidades ideológicas de ocupar este lugar.

As acusações de facilitação à dominação estrangeira atribuídas ao projeto do governo traziam, porém, o risco de a posição do Diário de Notícias ser vista como uma temerária aproximação com o "comunismo". Alguns articulistas importantes do jornal, como Rafael Correia de Oliveira e Joel Silveira, procuraram rechaçar esta possível interpretação associando-se ou dando voz a antigos e empedernidos combatentes do "perigo vermelho" que igualmente tinham se tornado novatos defensores do monopólio estatal do petróleo. Decorre daí, provavelmente, a importância do endosso a posição da UDN e de outros baluartes do conservadorismo, como o expresidente da República, o general Dutra (DIÁRIO DE NOTÍCIAS, 1952a, p. 5). Todavia, no que tange à posição oficial do Diário de Notícias, este se mostrou comedido ao não explicitar uma postura ideológica, insinuando apenas a necessidade de discussão do problema, sem apontar com clareza uma solução.

No decorrer das votações na Câmara dos Deputados, em uma flagrante contradição com a posição inicial, o Diário de Notícias assumiu uma postura tímida, não fazendo menções à inclusão do monopólio estatal no programa do governo e dando ênfase aos aspectos "liberais" do projeto que iria para análise no Senado. De qualquer maneira, Vargas continuou a ser o alvo essencial, não importando muito a corrente ideológica sobre a qual desejasse navegar com o seu programa. ${ }^{18}$ No que concerne à atuação udenista, que aceitou o projeto do governo com a manutenção das refinarias privadas, o jornal optou pelo silêncio, abstendo-se de criticar o seu aliado de até pouco tempo.

Durante a fase de tramitação do projeto no Senado, o Diário de Notícias foi o jornal que menos cobertura deu aos acontecimentos finais da questão do petróleo. Seus espaços de reportagem demonstraram equilíbrio de informações acerca das duas "soluções" para o problema petrolífero, embora esse periódico ainda apresentasse inclinação ao monopólio estatal, como evidenciou a matéria que cobriu a votação final no Senado. ${ }^{19}$ No entanto, em seus editoriais, o Diário de Notícias passou a assumir uma posição oficial sobre a contenda do petróleo, a qual não deixa de gerar surpresa, na medida em que começou a advogar pelo modelo de empresa de economia mista, sem jamais mencionar as iniciativas originais de Vargas nesta direção. ${ }^{20}$

Por conseguinte, percebe-se um curioso e sinuoso posicionamento do Diário de Notícias no que diz respeito à questão do petróleo. Primeiramente, desde o surgimento do Estatuto do Petróleo, o jornal mostrou-se um defensor intransigente do monopólio estatal, seguindo a mesma posição durante a apresentação das Mensagens Presidenciais em 1951 e ao longo dos debates na Câmara Baixa, quando desaprovou o modelo sugerido por Vargas. Entretanto, ao ser incluído o monopólio estatal no programa varguista e este ir para debate no Senado, o Diário de Notícias foi mudando sua posição, adotando o modelo de economia mista para a "solução" do problema do petróleo na medida em que Vargas se distanciava deste modelo...

\section{Conclusão}

Podemos observar padrões distintos no que concerne às atuações dos três jornais cariocas e suas representações sobre a UDN no caso da criação da Petrobras.

O jornal Última Hora, ao se associar às escolhas políticas do governo, acabou oscilando entre a defesa da empresa de economia mista e o monopólio estatal parcial do petróleo. Diante deste paradoxo, procurou, como forma de conciliar o seu apoio a Getúlio Vargas com um mínimo de coerência doutrinária, justificar o seu suporte à tese monopolista como um "sacrifício" em nome da conciliação e dos interesses do Brasil. O Diário de Notícias, por seu turno, caracterizou-se por ter grande flexibilidade de posicionamento, na medida em que moldou o seu discurso com o propósito de combater Vargas e o programa do petróleo, em um verdadeiro jogo de espelhos com o governo. Já o Correio da Manhã, após defender a forma da empresa de economia mista como modelo mais adequado ao Brasil, manteve-se coerente com esta alternativa até o fim do processo, apoiando Vargas quando este apresentou a sua proposta original e 
combatendo o presidente quando ele modificou o seu projeto em busca de um acordo político.

$\mathrm{Na}$ mesma medida, o posicionamento desses jornais em relação à UDN variou conforme o próprio partido do Brigadeiro se situava frente ao tema do petróleo e ao governo Vargas. No caso da do jornal Última Hora,, encontramos, no geral, críticas pesadas quando o partido se opôs às propostas de Vargas, apoiando o monopólio ou defendendo o liberalismo. Nos raros momentos em que a UDN convergiu com Getúlio, o jornal ficou entre a condescendência ou omissão diante deste aliado improvável. Já o Diário de Notícias tendeu a ver neste partido um parceiro no seu acirrado antivarguismo, elogiando-o nas vezes em que ele assumiu a crítica "nacionalista" aos programas do governo e silenciando nas oportunidades em que retornou à posição liberal. Por fim, o Correio da Manhã, longe de trilhar um caminho "udenista" como por vezes lhe é atribuído, foi muito crítico à UDN por seu oportunismo político e falta de coerência doutrinária, não se preocupando em ressaltar o partido sequer no momento em que os seus senadores quiseram "liberalizar" a Petrobras.

Em suma, vemos como a relação entre jornais e partidos políticos podia ser complexa quando interesses e questões importantes estavam em jogo nos anos de 1950, como no caso do petróleo. Embora este artigo esteja longe de ser conclusivo, ele pretende alertar para a necessidade de aprimoramento teórico-metodológico no tratamento do vínculo entre os grandes jornais e a política no período em questão, a qual não pode mais ser compreendida apenas pelos parâmetros simplistas apontados na introdução.

\section{Notas}

1 Conforme aponta Afonso Albuquerque (1998, p. 9), o paradigma da manipulação da notícia, ainda hegemônico nos estudos de comunicação nos anos 19902000, pode ser resumido da seguinte maneira: partindose da constatação de que a imprensa apresenta uma visão que se considera parcial ou distorcida da "realidade", conclui-se obrigatoriamente que isto foi resultado da manipulação consciente da informação com vista a atender os interesses superiores que se impuseram sobre os jornais.
2 Em relação à crítica a esta última noção, ver o trabalho de Abreu e Lattmann-Welltmann (1996).

3 Devemos lembram que o projeto original determinava que a União deveria deter o controle acionário da Pretrobras, tendo em vista que seria proprietária, por lei, de $51 \%$ de suas ações ordinárias da nova empresa, ou seja, daquelas que dão direito a voto no Conselho Diretivo da companhia. Ademais, a participação de capital privado se daria preferencialmente mediante impostos compulsórios a serem pagos pelos compradores de carros e consumidores de gasolina, sendo permitido que $15 \%$ deste montante fosse de origem estrangeira. Porém, o texto legal que propunha a criação da Petrobras abria a possibilidade de se ampliar o escopo de acionistas da empresa mediante venda de ações no mercado de capitais. Apesar de o documento prescrever que somente seriam vendidas ações preferenciais - ou seja, que não dão direito a voto, mas apenas a divisão dos lucros - os "nacionalistas" condenaram este dispositivo, vendo nele uma alternativa para o controle acionário da empresa pelos trustes internacionais do petróleo. Quanto a estes detalhes, consultar: Cohn (1968).

4 Quanto a estas posições ver: Martins (2010) e Carvalho Jr. (2005).

5 Os jornais foram consultados entre dezembro de 1951 e outubro de 1953, e encontram-se disponíveis no site da Hemeroteca Digital da Fundação Biblioteca Nacional: $<$ http://bndigital.bn.gov.br/hemeroteca-digital>.

6 As manchetes Última Hora, de 6 de dezembro de 1951, com as quais o projeto de Vargas é anunciado: "Vargas convoca o povo para a campanha de libertação", e "Governo e povo derrotam os monopólios", oferecem bons indícios de como esse jornal pretendia representar o programa do petróleo de Getúlio (ÚLTIMA HORA, 1951a, p. 1).

7 Na coluna Barômetro Econômico já havia aparecido a seguinte crítica ao partido: Neste sentido, a coluna "Barômetro Econômico", por exemplo, criticou a UDN da seguinte forma: "Não só a extrema esquerda, comunista e trabalhista, se batem pela estatização do petróleo [...]; um dos partidos conservadores, tradicionalmente defensor da iniciativa privada em face da tendência do Estado para empreender a solução dos grande problemas do país, adere à corrente do monopólio estatal sem muitas considerações sobre o seu passado, pelos interesses econômicos da Nação, ou pela sua própria defesa" (ÚLTIMA HORA, 1952c, p. 6)

8 Em 15 de maio de 1952, a coluna "Barômetro Econômico" afirmou que a proposta da criação da ENAPE suscitava muitas suspeitas, ainda mais "saída de um partido conservador como a UDN. Os propósitos que animaram seus autores são, evidentemente, de ordem político-partidários, pouco tendo a ver com o problema do petróleo" (ÚlTIMA HORA, 1952d, p. 6). Em no editorial de 16 de maio de 1952, comparando o projeto da UDN e o programa de Vargas ("PETROBRAS $\mathrm{x}$ 
ENAPE”), o jornal foi mais além, citando que prevaleceu “[...], portanto, na UDN, o objetivo protelatório da ala demagógica do partido contra a orientação esclarecida do seu presidente. A demagogia pequeno-burguesa não vacilou, mais uma vez, em prejudicar os interesses nacionais, em proveito de duvidosos sucessos eleitorais" (ÚLTIMA HORA, 1952e, p. 3).

9 Ver quanto a esta estratégia do jornal como linha editorial em outros temas o trabalho de Goldenstein (1987).

10 Como podemos perceber pela seguinte reportagem "Vitória da Petrobras na Câmara": "Será, hoje, finalmente, a votação da Petrobras na Câmara dos Deputados. A proposição para a solução do problema de nossas reservas petrolíferas terá a sua marcha acelerada no período da votação, em face do entendimento a que chegaram os líderes da maioria e da minoria no decurso da semana que findou. Em torno da quase unanimidade das disposições contidas no projeto da Petrobras houve conciliação (ÚLTIMA HORA, 1952g, p. 1).

11 Como podemos ver pelo próprio título da matéria de 30 de maio de 1953: "Ampla vitória do governo no Senado: O petróleo não será entregue aos trusts" (ÚLTIMA HORA, 1953h, p. 3).

12 Em 18 de novembro de 1953, o Última Hora publicou: "Ora, a nação conhece, minuciosamente, o que foi o dramático debate do petróleo na Câmara dos Deputados. E presenciou, sob aplausos, o procedimento do Governo, receptível às reivindicações doutrinárias dos demais parlamentares. Daí surgiu a Petrobras, agora, como a média do pensamento político brasileiro a respeito do problema do petróleo. A solução ali apresentada, se consulta aos mais altos interesses do país, pelo seu caráter nacionalista, sem prejudiciais exageros, ganha plena autoridade por ser o resultado de uma conciliação das nossas forças políticas atuantes. Falaram os partidos, trabalharam os líderes, manifestaram-se os congressistas - e a 'Petrobras' foi encaminhada ao Senado baseada nessa incontestável autoridade partidária (ÚLTIMA HORA, 1953j, p. 3).

13 O Correio da Manhã condenou arduamente a forma como o tema vinha sendo debatido quando da apresentação do programa de Vargas. No dia 08 de dezembro de 1951, ao tratar do projeto do governo, o jornal ressalta que a "matéria exige, portanto, a colaboração independente de todos os brasileiros" e que ela é "do mais relevante interesse público e, ao mesmo tempo, de caráter absolutamente técnico". Desta forma, "é indispensável que o projeto do governo seja escoimado de qualquer empirismo e apreciado sem o menor cunho partidário, quer favorável, quer adverso" (CORREIO DA MANHÃ, 1951, p. 4).

14 Em um contundente editorial, o jornal pergunta: "Por que adotou o governo a fórmula nacional-comunista? Que fins procurou atingir? ” O próprio Correio responde: "A resposta, única e verdadeira, é a seguinte: porque o sr. Getúlio Vargas, diante da voga de que goza o slogan do 'petróleo é nosso' nos meios mais primários do país, deseja encampar essa chapa para uso próprio. Então se dirá que 'ele disse que o petróleo é nosso'. E isso é que é o nacionalismo, segundo o sr. Getúlio Vargas (CORREIO DA MANHÃ, 1952c, p. 4).

$15 \mathrm{O}$ que podemos resumir por este editorial do Diário de Notícias (1951, p. 4): "Examinar o projeto à base da tese nacionalista e criticá-lo severamente porque, além de representar uma concessão a empresas estrangeiras, obriga o povo a contribuir para o esforço de ganho das companhias alienígenas; achar conveniente a solução encontrada pelo governo e ter cuidado na enunciação da verdade, implícita no projeto, apesar de todos os disfarces, que a colaboração estrangeira se tornou imprescindível e a administração do Brasil não lhe pode fugir”.

16 Como podemos notar nos títulos das seguintes reportagens: "Manifesta-se a UDN pela exploração estatal do Petróleo" (DIÁRIO DE NOTÍCIAS, 1952c, p. 3) e "Congratulação com a UDN pela adoção da tese do monopólio estatal” (DIÁRIO DE NOTÍCIAS, 1952d, p. 3).

17 Lembrando o papel do partido na queda de Getúlio, em 1945, o articulista Rafael Oliveira salientou: "Se o partido tomar em 1952, a posição que assumiu em 1945, passará à história, definitivamente, com a mais fecunda e gloriosa força política do Brasil em todos os tempos. E poderá plantar nas suas linhas invictas o estandarte da soberania nacional triunfante, sem abalos perigosos nem derramamento de sangue - nos moldes civilizados da abolição" (DIÁRIO DE NOTÍCIAS, 1952b, p. 5),

18 Conforme se lê, em 21 de junho de 1952, no editorial do Diário de Notícias: em um editorial do DN: No Catete, o "ex-ditador embarca noutra canoa, e lança ao mar $[(. .]$.$) a tese, a bandeira do 'monopólio$ estatal', que notoriamente arvorou durante a campanha presidencial, por ser a mais popular, por conseguinte, a mais própria para a colheita de voto" (DIÁRIO DE NOTÍCIAS, 1952e, p. 4).

19 O Diário de Notícias, em 10 de junho de 1953, menciona: "Vitoriosa, no conjunto da votação do Senado, a tese monopolista do Petróleo", e, depois pelo texto: "congratulando-se (os senadores) com a Casa pelo estudo profundo e minucioso do importante problema da exploração do petróleo brasileiro. Também o sr. Domingos Velasco salientou a vitória, depois de longa luta, da tese do monopólio estatal, e o aperfeiçoamento do projeto através de emendas, principalmente as de iniciativa do Sr. Alberto Pasqualini" (DIÁRIO DE NOTÍCIAS, 1953g, p. 3).

20 Nas palavras do jornal, publicadas em 24 de abril de 1953, a única solução para o problema do petróleo era aquela que "assegurasse à União, as autarquias ou empresas paraestatais, a maioria de ações na sociedade de 
economia mista a se constituir, atendendo a que o capital particular nacional ou alienígena pudesse igualmente subscrever ações até o limite previsto em lei, assegurando aos acionistas direito que a legislação já concede de voto em assembleias da sociedade" (DIÁRIO DE NOTÍCIAS, 1953f, p. 4).

\section{Referências}

ABREU, A.; LATTMANN-WELLTMANN, F. Fechando o cerco: a imprensa e a crise de agosto de 1954. In: GOMES, Â. (Org.). Vargas e a crise dos anos 50. Rio de Janeiro: Relume-Dumará, 1994. p. 23-60

A Imprensa em Transição: O Jornalismo Brasileiro nos anos 50. Rio de Janeiro Fundação Getúlio Vargas, 1996.

ALBUQUERQUE, A. Manipulação editorial e produção da notícia: dois paradigmas da análise da cobertura jornalística da política. In: RUBIM, A. A. C.; BENTZ, I. M. G.; PINTO, M. J. (Org.). Produção e recepção dos sentidos midiáticos. Rio de Janeiro; Petrópolis: Vozes, 1998. p.9-27.

CARVAlHO JR., C. A criação da Petrobras nas páginas dos jornais $\mathrm{O}$ Estado de São Paulo e Diário de Notícias. 2005. 180 f. Dissertação (Mestrado em História) - Programa de PósGraduação em História, Faculdade de Ciências e Letras da Universidade Estadual Paulista "Júlio de Mesquita Filho", Assis, 2005.

COHN, G. Petróleo e Nacionalismo. São Paulo: Difusão Européia do Livro, 1968. (Coleção Corpo e Alma do Brasil).

CORREIO DA MANHÃ. Rio de Janeiro, 8 dez. 1951, cad. 1, p. 4. Disponível em: <http://bndigital.bn.gov. br/hemeroteca-digital $>$. Acesso em: jul. 2015.

Rio de Janeiro, 11 maio 1952a, cad. 1, p. 4. Disponível em: <http://bndigital.bn.gov.br/ hemeroteca-digital>. Acesso em: jul. 2015.

Rio de Janeiro, 6 jul. 1952b, cad. 1, p. 4. Disponível em: <http://bndigital.bn.gov.br/ hemeroteca-digital>. Acesso em: jul. 2015.
Rio de Janeiro, 3 set. 1952c, cad. 1, p. 4. Disponível em: <http://bndigital.bn.gov.br/ hemeroteca-digital $>$. Acesso em: jul. 2015.

Rio de Janeiro, 9 set. 1952d, cad. 1, p. 4. Disponível em: <http://bndigital.bn.gov.br/ hemeroteca-digital $>$. Acesso em: jul. 2015.

Rio de Janeiro, 11 abr. 1953e, cad. 1, p. 4. Disponível em: <http://bndigital.bn.gov.br/ hemeroteca-digital >. Acesso em: jul. 2015.

Rio de Janeiro, 28 maio 1953f, cad. 1, p. 4. Disponível em: <http://bndigital.bn.gov.br/ hemeroteca-digital >. Acesso em: jul. 2015.

DIÁRIO DE NOTÍCIAS. Rio de Janeiro, $12 \mathrm{dez}$. 1951, cad. 1, p. 4. Disponível em: <http://bndigital. bn.gov.br/hemeroteca-digital>. Acesso em: jul. 2015.

Rio de Janeiro, 19 mar. 1952a, cad. 1, p. 5. Disponível em: <http://bndigital.bn.gov.br/ hemeroteca-digital $>$. Acesso em: jul. 2015.

Rio de Janeiro, 30 abr. 1952b, cad. 1, p. 5. Disponível em: <http://bndigital.bn.gov.br/ hemeroteca-digital >. Acesso em: jul. 2015.

Rio de Janeiro, 1 maio 1952c, cad. 1, p. 3. Disponível em: <http://bndigital.bn.gov.br/ hemeroteca-digital $>$. Acesso em: jul. 2015.

Rio de Janeiro, 2 maio 1952d, cad. 1, p. 3. Disponível em: <http://bndigital.bn.gov.br/ hemeroteca-digital $>$. Acesso em: jul. 2015.

Rio de Janeiro, 21 jun. 1952e, cad. 1, p. 4. Disponível em: <http://bndigital.bn.gov.br/ hemeroteca-digital >. Acesso em: jul. 2015.

Rio de Janeiro, 24 abr. 1953f, cad. 1, p. 4. Disponível em: <http://bndigital.bn.gov.br/ hemeroteca-digital $>$. Acesso em: jul. 2015.

Rio de Janeiro, 10 jun. 1953g, cad. 1, p. 3. Disponível em: <http://bndigital.bn.gov.br/ hemeroteca-digital $>$. Acesso em: jul. 2015. 
GOLDENSTEIN, G. Do jornalismo político à indústria cultural. São Paulo: Summus, 1987.

LAURENZA, A. M. A. Lacerda x Wainer: o Corvo e o Bessarabiano. 2 ed. São Paulo: Ed. SENAC, 1998.

MARTINS, L. C. P. A grande imprensa "liberal" da Capital Federal (RJ) e a política do segundo governo Vargas (1951-1954): conflito entre projetos de desenvolvimento nacional. 2010. 360 f. Tese (Doutorado em História) - Pontifícia Universidade Católica do Rio Grande do Sul, Porto Alegre, 2010.

MIRANDA, M. T. O Petróleo É Nosso: a luta contra o "entreguismo" pelo monopólio estatal (19471953) (1953-1981). Petrópolis: Vozes, 1983.

MOURA, G. A Campanha do Petróleo. Rio de Janeiro: Brasiliense, 1986. (Coleção Tudo É História).

PEREIRA, J. S. Petróleo, Energia Elétrica, Siderurgia: A luta pela emancipação. Rio de Janeiro: Paz e Terra, 1975.

RIBEIRO, A. P. G. Jornalismo, literatura e política: a modernização da imprensa carioca nos anos 1950.

Estudos Históricos, Mídia, n. 31, p. 147-160, 2003.

SILVA, H. 1954: Um tiro no coração. Rio de Janeiro: Civilização Brasileira, 1978.

SODRÉ, N. W. História da imprensa no Brasil. São Paulo: Martins Fontes, 1983.

ÚlTIMA HORA. Rio de Janeiro, 6 dez. 1951a, cad. 1, p. 1. Disponível em: <http://bndigital.bn.gov. br/hemeroteca-digital>. Acesso em: dez. 2015.
Rio de Janeiro, 7 dez. 1951b, cad. 1, p. 1. Disponível em: <http://bndigital.bn.gov.br/ hemeroteca-digital >. Acesso em: dez. 2015.

. Rio de Janeiro, 14 maio 1952c, cad. 1, p. 6. Disponível em: <http://bndigital.bn.gov.br/ hemeroteca-digital>. Acesso em: dez. 2015.

Rio de Janeiro, 15 maio 1952d, cad. 1, p. 6. Disponível em: <http://bndigital.bn.gov.br/ hemeroteca-digital>. Acesso em: dez. 2015.

Rio de Janeiro, 16 maio 1952e, cad. 1, p. 3. Disponível em: <http://bndigital.bn.gov.br/ hemeroteca-digital>. Acesso em: dez. 2015.

. Rio de Janeiro, 6 jun. 1952f, cad. 1, p. 3. Disponível em: <http://bndigital.bn.gov.br/ hemeroteca-digital>. Acesso em: dez. 2015.

. Rio de Janeiro, 1 set. 1952g, cad. 1, p. 1. Disponível em: <http://bndigital.bn.gov.br/ hemeroteca-digital>. Acesso em: dez. 2015.

Rio de Janeiro, 30 maio 1953h, cad. 1, p. 2. Disponível em: <http://bndigital.bn.gov.br/ hemeroteca-digital>. Acesso em: dez. 2015.

. Rio de Janeiro, 7 ago. 1953i, cad. 1, p. 3. Disponível em: <http://bndigital.bn.gov.br/ hemeroteca-digital>. Acesso em: dez. 2015.

Rio de Janeiro, 8 nov. 1953j, cad. 1, p. 3. Disponível em: <http://bndigital.bn.gov.br/ hemeroteca-digital >. Acesso em: dez. 2015.

WIRTH, J. D. A Política do desenvolvimento na Era de Vargas. Tradução de Jefferson Barata. Rio de Janeiro: Fundação Getúlio Vargas, 1973. 